\title{
Understanding the role of genetics in childhood acute lymphoblastic leukemia (Review)
}

\author{
ELENI KAMPOURAKI ${ }^{1}$, GEORGE N. GOULIELMOS ${ }^{2}$ and EFTICHIA STIAKAKI ${ }^{1}$ \\ ${ }^{1}$ Department of Pediatric Hematology-Oncology and Laboratory of Blood Diseases and Childhood Cancer Biology, \\ Medical School, University of Crete; ${ }^{2}$ Section of Molecular Pathology and Human Genetics, \\ Department of Internal Medicine, Medical School of Crete, 71303 Heraklion, Greece
}

Received March 11, 2020; Accepted June 5, 2020

DOI: $10.3892 /$ wasj.2020.54

\begin{abstract}
Single nucleotide polymorphisms (SNPs), the most common type of genetic variation, are important for the study of human diseases. Genome-wide association studies (GWAS) have revealed specific gene polymorphisms, among hundreds of polymorphisms, that are associated with a number of diseases. Leukemia is one of these human pathologies, while acute lymphoblastic leukemia (ALL) is the most common type of cancer affecting children and adolescents. Despite progress being made in survival rates during over the past decades, ALL remains the second leading cause of cancer-related mortality in this age group. Consequently, early diagnosis and treatment remain a major clinical challenge. Several gene polymorphisms have been investigated concerning susceptibility to ALL, including SNPs of carcinogen metabolism genes, folate metabolism genes, DNA repair genes, regulators of lymphoid cell differentiation, tumor suppressors, transcriptional factors and chemokines. Furthermore, various SNPs of genes participating in the metabolism of anti-leukemic agents have revealed associations with therapy-toxicity. This is important, since therapy-induced toxicity may lead to interruptions or to the discontinuation of therapy, with the risk of relapse. Finally, SNPs of various genes have been related to the prognostic outcomes of patients with ALL. For these reasons, the present review aimed to describe the role of the above-mentioned SNPs as regards susceptibility, toxicity and the clinical outcome of ALL.
\end{abstract}

Correspondence to: Professor Eftichia Stiakaki, Department of Pediatric Hematology-Oncology and Laboratory of Blood Diseases and Childhood Cancer Biology, Medical School, University of Crete, Voutes, 71303 Heraklion, Greece

E-mail: efstel@med.uoc.gr

Key words: acute lymphoblastic leukemia, gene polymorphisms, children, single nucleotide polymorphisms, leukemia

\section{Contents}

1. Introduction

2. Susceptibility alleles

3. Role of genetic alterations in anti-leukemic drug toxicity

4. Prognosis/outcomes

5. Conclusion

\section{Introduction}

SNPs are the most common genetic variation among individuals. They consist of a replacement at a single base pair. Polymorphisms normally occur throughout the DNA of a subject and it has been estimated that 10 million polymorphisms exist in the human genome (Genetics Home Reference; https://ghr.nlm.nih.gov/primer/genomicresearch/snp). Depending on its location, an SNP can affect either the function and relevant biochemical pathways of a gene, or the development of a disease. Most commonly, polymorphisms are located in spacer DNA between genes or in non-coding regions. They may serve as biological markers for the identification of genes that may be associated with a disease. When they are located within a gene or in a regulatory region of a gene, they may affect the function of the gene and play a more direct role in the development of a disease (https://ghr.nlm.nih.gov/primer/genomicresearch/snp).

The majority of polymorphisms do not affect human health and do not lead to disease development. However, some of them play an important role in the study of diseases. They may contribute to the prediction of the response to treatment, susceptibility to toxins or the appearance of adverse events, as well as risk of development of specific diseases. They may also aid in enhancing our understanding of the inheritance of disease genes within families.

Genome-wide association studies (GWAS) are studies that investigate the whole genome for the detection of SNPs that are associated with a disease. Each study can analyze hundreds of thousands of polymorphisms simultaneously. The data from this analysis can identify gene modifications that may render an individual susceptible for developing a certain disease. This approach has already revealed various polymorphisms associated with several complex pathologies 
including diabetes (1), heart abnormalities (2), Parkinson's disease (3), Crohn's disease (4), cancer (5) and hematological malignancies (6), i.e., leukemia (7).

In particular, focusing on ALL, Wang et al (7) demonstrated that the combination of SNP array analysis with chromosome and fluorescence in situ hybridization (FISH) assays in patients with ALL significantly increased the detection rate for clinically significant abnormal conditions (from 56 to $75 \%$ ). The authors of that study suggested that as whole genome SNPs array analysis can detect cytogenetically undetectable clinically significant aberrations, this approach could routinely be applied to the diagnosis of ALL (7). As regards pediatric patients, leukemia is the most common type of childhood cancer. It is estimated that it accounts for $25.8 \%$ of all malignancies in patients $<20$ years of age and is the second leading cause of cancer-related mortality in this age group. When ALL is compared to acute myelogenous leukemia (AML), it occurs 5-fold more frequently in this population. It is estimated that $78 \%$ of childhood leukemia is ALL (8). Approximately $85 \%$ of all pediatric ALL cases are B-lineage derived and due to the above findings, the early diagnosis and treatment of childhood ALL comprise a major challenge. In the present review, the role of specific SNPs in the clinical aspects of susceptibility to disease, therapy-toxicity and prognosis/outcomes are further presented and summarized.

\section{Susceptibility alleles}

As categorized in Table I, there are several genes whose SNPs are related to susceptibility to pediatric ALL.

A systematic review and meta-analysis of published studies (January, 1996 to Jully, 2009) was conducted in 2010 (9), with the aim of understanding the role of candidate genes in the susceptibility to childhood ALL. In total, 25 polymorphic variants were analyzed, belonging to the following categories: Carcinogen metabolism genes, folate metabolism genes and DNA repair genes.

Carcinogen metabolism-related genes (xenobiotic system) include phase I enzymes that include cytochrome P4501A1 (CYP1A1), phase II enzymes that include glutathione S-transferases [glutathione S-transferase M1 (GSTM1) and glutathione S-transferase theta 1 (GSTT1)], NADPH quinone oxidoreductase $1(\mathrm{NQOl})$ and multidrug resistance protein 1 $(M D R l)$, which encodes the P-glycoprotein. Folate metabolism genes refer to 5,10-methylenetetrahydrofolate reductase (MTHFR), methionine synthase (MTR alias $M S)$, methionine synthase reductase $(M T R R)$, serine hydroxymethyltransferase $(S H M T)$, thymidylate synthetase $(T S)$ and reduced folate carrier 1 ( $R F C 1$, alias SLC19A1). DNA repair genes include $\mathrm{X}$-Ray repair-cross complementing group 1 (XRCC1) and excision repair-complementing group 2 (ERCC2). Significant associations were revealed in a pooled analysis for 8 variants, particularly GSTM1 deletion, MTRR A66G, SHMT1 C1420T, RFC1 G80A, CYP1A1*2A, CYP2E1*5B, NQO1 C609T and $X R C C 1 \mathrm{G} 28152 \mathrm{~A}$. Conclusively, it was suggested that candidate gene analyses may be used complementary to GWAS (9).

Phase I enzymes. CYPIAl is a gene that has been investigated concerning its possible susceptibility for ALL. CYP1A1 belongs to family 1 , subfamily $1 \mathrm{~A} 1$ of cytochrome
P450. CYP1A1 protein is a phase I xenobiotic-metabolizing enzyme. It is involved in the activation of the conversion of environmental chemicals into carcinogens (particularly polycyclic aromatic hydrocarbons). In the next step, phase II enzymes, such as GSTM1, detoxify the above carcinogens. Genetic polymorphisms of $C Y P I A l$ have been investigated concerning their negative effects on enzyme function and as a result, on the metabolizing ability (10). CYPIAl harbors two important polymorphisms, rs4646903 (T3801C), which is also referred to as $C Y P 1 A 1 * 2 A$, localized to chromosome $15 q 22$, and rs1048943 (A2455G), which is also referred to as CYP1A $1 * 2 \mathrm{C}$ or $\mathrm{m} 2$ allele. A previous meta-analysis revealed that the $C Y P 1 A 1 * 2 A$ and $C Y P 1 A 1 * 2 C$ alleles increased the risk of developing leukemia and that there may exist a variation regarding ethnicity, gene-gene interactions, age and leukemia subtype (11).

Phase II enzyme. A previous meta-analysis concerning the role of the GSTP1 A15578G polymorphism in ALL revealed no connection between the above-mentioned polymorphism and the risk of developing ALL (12). Similarly, another meta-analysis investigating the role of polymorphisms of GSTM1, GSTT1 and GSTP1 Ile105Val in childhood ALL revealed that the GSTM1 variants may increase the risk of developing ALL. However, no association was found with regard to the other polymorphisms (13).

Folate metabolism genes. Some polymorphisms in folate pathway genes may be associated to the risk of developing ALL. Two MTHFR gene polymorphisms, C677T and A1298C, seem to play a protective role through a gene-environment interaction, as shown by a study including 270 patients with ALL of French-Canadian origin (14). Moreover, another study including 245 pediatric patients with ALL investigated the role of polymorphisms in MTHFR $(677 \mathrm{C}>\mathrm{T}, 1298 \mathrm{~A}>\mathrm{C})$, methionine synthase $(M T R \quad 2756 \mathrm{~A}>\mathrm{G})$, methionine synthase reductase (MTRR 66A $>\mathrm{G}$ ), methylenetetrahydrofolate dehydrogenase (MTHFD1 1958G>A), nicotinamide $\mathrm{N}$-methyltransferase (NNMT IVS-151C $>\mathrm{T}$ ), serine hydroxymethyl transferase (SHMT11420C $>\mathrm{T}), T S(2 \mathrm{R} 3 \mathrm{R})$ and reduced folate carrier ( $R F C 180 \mathrm{G}>\mathrm{A})$; an increased risk of developing ALL was revealed for the $R F C 1$ and $N N M T$ gene variants, whereas a decreased risk of developing ALL was revealed for the MTHFR and TS gene variants (15). The authors of that study suggested that the reduced cellular uptake of folate and a change in the methylation status was responsible for the increased risk of developing ALLassociated with $R F C 180 \mathrm{G}>\mathrm{A}$ and NNMT IVS-151C $>$ T. They also suggested that a change in the intracellular folate redistribution may be the reason for the reduced risk of developing ALL for subjects possessing the MTHFR $677 \mathrm{C}>\mathrm{T}$ and $T S 2 R / 3 R$ polymorphisms (15). Another study that included 392 Australian patients with ALL and their parents investigated the role of 7 folate pathway gene polymorphisms (MTHFR 677C $>\mathrm{T}$, MTHFR 1298A >C, MTRR 66A $>\mathrm{G}$, MTR $2756 \mathrm{~A}>\mathrm{G}, M T R 5049 \mathrm{C}>\mathrm{A}, C B S 844$ Ins68 and $C B S$ $2199 \mathrm{~T}>\mathrm{C}$ ) in association with pre-pregnancy maternal folic acid supplement use (16). The data analysis revealed that the children who had, or whose father had the MTRR 66GG genotype exhibited a reduced risk of developing ALL. The above results indicate that some folate pathway gene polymorphisms 
Table I. Overview of the genetic loci associated with susceptibility to ALL.

\begin{tabular}{|c|c|c|c|}
\hline Gene & Function/role & Author, year of publication & (Refs.) \\
\hline CYP1A1 & Carcinogen metabolizing enzyme & $\begin{array}{l}\text { Vijayakrishnan and Houlston, } 2010 \\
\text { Han et al, } 2013\end{array}$ & $\begin{array}{l}(9) \\
(11)\end{array}$ \\
\hline CYP2E1 & Carcinogen metabolizing enzyme & Vijayakrishnan and Houlston, 2010 & $(9)$ \\
\hline GSTM1 & Carcinogen metabolizing enzyme & $\begin{array}{l}\text { Vijayakrishnan and Houlston, } 2010 \\
\text { Zhao et al, } 2018\end{array}$ & $\begin{array}{l}(9) \\
(13)\end{array}$ \\
\hline$N Q O 1$ & Carcinogen metabolizing enzyme & Vijayakrishnan and Houlston, 2010 & (9) \\
\hline$M D R 1$ & Carcinogen metabolizing enzyme & Kreile et al, 2014 & $(17)$ \\
\hline MTHFR & Folate metabolism gene & $\begin{array}{l}\text { Krajinovic et al, } 2004 \\
\text { de Jonge } \text { et al, } 2009 \\
\text { Kreile et al, } 2014\end{array}$ & $\begin{array}{l}(14) \\
(15) \\
(17)\end{array}$ \\
\hline $\operatorname{MTR}(M S)$ & Folate metabolism gene & $\begin{array}{l}\text { de Jonge et al, } 2009 \\
\text { Ma et al, } 2019\end{array}$ & $\begin{array}{l}(15) \\
(19)\end{array}$ \\
\hline MTRR & Folate metabolism gene & $\begin{array}{l}\text { Vijayakrishnan and Houlston, } 2010 \\
\text { Milne et al, } 2015\end{array}$ & $\begin{array}{l}(9) \\
(16)\end{array}$ \\
\hline SHMT1 & Folate metabolism gene & Vijayakrishnan and Houlston, 2010 & (9) \\
\hline RFCl & Folate metabolism gene & $\begin{array}{l}\text { Vijayakrishnan and Houlston, } 2010 \\
\text { De Jonge et al, } 2009\end{array}$ & $\begin{array}{l}(9) \\
(15)\end{array}$ \\
\hline$N N M T$ & Folate metabolism gene & De Jonge et al, 2009 & $(15)$ \\
\hline$X R C C 1$ & DNA repair gene & Vijayakrishnan and Houlston, 2010 & (9) \\
\hline$A R I D 5 B$ & Regulator of B-cell differentiation & $\begin{array}{l}\text { Papaemmanuil et al, } 2009 \\
\text { Rudant et al, } 2015 \\
\text { Archer et al, } 2017 \\
\text { Xu et al, } 2013 \\
\text { Bhandari et al, } 2016\end{array}$ & $\begin{array}{l}(24) \\
(25) \\
(26) \\
(27) \\
(29)\end{array}$ \\
\hline$I K Z F 1$ & $\begin{array}{l}\text { Regulator of B-cell differentiation } \\
\text { Tumor suppressor }\end{array}$ & $\begin{array}{l}\text { Papaemmanuil et al, } 2009 \\
\text { Rudant et al, } 2015 \\
\text { Xu et al, } 2013 \\
\text { Bhandari et al, } 2016\end{array}$ & $\begin{array}{l}(24) \\
(25) \\
(27) \\
(29)\end{array}$ \\
\hline$C E B P E$ & Regulator of B-cell differentiation & $\begin{array}{l}\text { Papaemmanuil et al, } 2009 \\
\text { Xu et al, } 2013\end{array}$ & $\begin{array}{l}(24) \\
(27)\end{array}$ \\
\hline BMI1-PIP4K2A & Regulator of lymphoid cell differentiation & $\mathrm{Xu}$ et al, 2013 & $(27)$ \\
\hline$C D K N 2 A$ & Tumor suppressor & $\begin{array}{l}\text { Xu et al, } 2013 \\
\text { Walsh et al, } 2015\end{array}$ & $\begin{array}{l}(27) \\
(28)\end{array}$ \\
\hline GATA3 & GATA family of transcription factors & Hou et al, 2017 & $(30)$ \\
\hline CXCL12 & Chemokine expressed in various tumors & de Lourdes Perim et al, 2013 & $(31)$ \\
\hline TP53 & Tumor suppressor & de Lourdes Perim et al, 2013 & $(31)$ \\
\hline Inc-LAMC2 & Long non-coding RNAs & Hashemi et al, 2016 & (32) \\
\hline MicroRNAs & Target gene expression & Xue et al, 2019 & $(33)$ \\
\hline
\end{tabular}

in the child or a parent may influence the risk of developing ALL (16). In addition, a study on 68 patients with ALL in Latvia demonstrated no significant association between polymorphisms in both MDRl (rs1045642 and rs2032582) and MTHFR (rs1801131 and rs1801133) gene polymorphisms and an increased risk of developing ALL; however, that study demonstrated an age-related association (17). As regards the thymidylate synthase enhancer region (TSER) variation, a previous quantitative meta-analysis revealed that it was not related to the risk of developing pediatric ALL (18).

Finally, a meta-analysis including 10 available studies with 3,224 ALL cases and 4,077 matched controls was performed by Ma et al (19) in order to evaluate the association of the methionine synthase (MTR) A2756G polymorphism with the risk of developing pediatric ALL. The results of that study revealed that there was a significant association between the MTR A2756G polymorphism and the risk of developing pediatric ALL in the overall population. Following stratification analyses, the authors of that study suggested that the risk of developing pediatric ALL in Caucasians may be influenced by the MTR A2756G polymorphism (19).

Other gene categories. GWAS have also been used to test 2 polymorphisms, AT-rich interactive domain $5 \mathrm{~b}$ gene (ARID5B, 
chromosomal region 10q21.2) and Ikaros family zinc finger 1 gene (IKZF1, chromosomal region 7p12.21). They revealed that these SNPs may be associated with an increased risk of developing pediatric ALL and pointed out that these two genes were involved in lymphoid differentiation. In particular, Ikaros is a necessary component for B-cell development and is also required for the expression of B-cell receptors (20). Moreover, it is also a tumor suppressor (21). In the case of a genetic alteration of this gene, a poor outcome for B-cell-progenitor ALL has been observed $(22,23)$. Of note, 3 risk loci were identified in a study including 907 patients with ALL and 2,398 controls, rs 4132601 of the IKZFI gene (7p12.2), rs7089424 of the ARIDB5 gene (10q21.2) and rs2239633 of the CEBPE gene (14q11.2). All the risk alleles of the 3 polymorphisms under study map to genes that regulate the transcription and the differentiation of B-cell progenitors. The rs7089424 of ARIDB5 gene was revealed in B-cell precursor ALL with hyperdiploidy (24). A study named ESCALE investigated whether there was any association between these SNPs and other non-genetic risk factors, such as the maternal use of home insecticides during pregnancy, preconception paternal smoking, breastfeeding, infections before the age of 1 and birth order (25). The authors investigated rs10740055 of $A R I D 5 B$ or rs 4132601 of IKZFI and each of the suspected non-genetic factors, with the SNPs recorded as counts of minor alleles (trend variable). They observed an association between rs4132601 and maternal insecticide use, breastfeeding and repeated early common infections (25). The role of ARID $5 B$ in childhood ALL susceptibility was also confirmed by another exome-wide association study that included 710 individuals from Hispanic families. Two SNPs of the ARID5B gene, rs10821936 and rs7089424, reached at genome-wide level of significance (26). The ALL-susceptibility loci (IKZFI and $A R I D 5 B$ ) were also validated by a multiethnic GWAS performed in 2013 (27). Of interest, that study revealed a novel ALL susceptibility locus, BMI1-PIP4K2A (rs7088318) located at 10p12.31-12.2, revealing an independent replication in European Americans, African Americans and Hispanic Americans (27). Furthermore, that study also validated 4 already known ALL risk polymorphisms of the CCAAT enhancer-binding protein epsilon $(C E B P E)$ and cyclin-dependent kinase inhibitor $2 \mathrm{~A}(C D K N 2 A / 2)$ genes. $C E B P E$ is a transcription factor involved in the regulation of myelopoiesis (24), whereas $C D K N 2 A$ is a gene that provides instructions for making protein-tumor suppressors. The fact that $C D K N 2 \mathrm{~A}$ polymorphisms confer a strong risk for developing childhood ALL was previously demonstrated by Walsh et al (28). DKN2A missense variant (rs3731249) was revealed to confer a 3-fold increased risk of developing ALL in children of European ancestry and Hispanic children. Furthermore, the same study suggested that the risk allele may provide an advantage for tumor development and is selected during clonal evolution. The role of the rs10821936 SNP of ARID5B and rs4132601 SNP of $I K Z F I$ was also previously investigated in an Indian population (162 de novo B-lineage ALL) and it was found that both SNPs were associated with a decreased risk of B-lineage for Indian children (29).

Another gene investigated with regard to pediatric ALL is GATA3, which belongs to the GATA family of transcription factors. A genome-wide gene expression association analyses examined 9 independent B-ALL patient cohorts to reveal a possible association between genes expression and pathways. The results revealed that some SNPs may affect the association between GATA3 expression and its targets, e.g., rs4894953 located in the potential GATA3 binding motif (30).

The CXCL12 and TP53 gene polymorphisms have also been investigated as markers of susceptibility to childhood ALL. A previous study including 54 Brazilian patients and 58 controls demonstrated that the frequencies of both allelic variants analyzed together (rs1801157 of CXCL12 and rs1042522 of TP53) significantly increased the risk of developing ALL $>5$-fold (31).

Furthermore, polymorphisms of long non-coding RNAs (IncRNAs) have also been investigated in association with the development of ALL. IncRNAs represent a novel class of non-protein coding RNAs, which can affect various biological processes. The role of rs2147578 of Inc-LAMC2-1:1 and rs10505477 of $C A S C 8$ was investigated in previous a study that included 110 Iranian patients and 120 healthy controls, and it was found that Inc-LAMC2-1:1 rs2147578 may be associated with a higher risk of developing ALL (32).

Finally, microRNAs (miRNAs or miRs) that are small, non-coding RNA molecules, which consist of 22 nucleotides and play a role in targeting gene expression, were investigated in a previous Chinese study including 831 childhood patients with ALL and 1,079 controls. That study revealed a significant association between the polymorphisms in miR-100 (rs543412) and a decreased risk of developing ALL, thus suggesting that this variant was a protective factor for ALL (33).

\section{Role of genetic alterations in anti-leukemic drug toxicity}

Children with ALL are treated with multi-agent chemotherapeutic regimens, the toxicity of which may affect the quality of life of patients and their families during the treatment period and following cancer therapy. Sometimes, the related toxicity is more severe and can lead to interruptions or the discontinuation of therapy with the risk of relapse. Less frequently, toxicity due to treatment may be life-threatening. The prediction of toxicity is difficult due to differences among patients concerning pharmacokinetics and pharmacodynamics of anti-leukemic agents. There are inherited polymorphisms in genes of enzymes that metabolize drugs, in genes of transporters or in genes of targets and receptors. The SNPs that may influence the toxicity for anticancer agents are presented in Table II.

A candidate-gene approach was used in previous a study aiming to examine whether an association existed between toxicity (gastrointestinal, infection, hyperbilirubinemia and neurotoxicity) and 16 common polymorphisms in genes involved in the pharmacodynamics of ALL in 240 patients (34). The authors of that study observed that during the induction phase, the genotypes for certain genes participating in that pathway played a crucial role. Vitamin D receptor and cytochrome P4503A5 polymorphisms were found to exhibit an association concerning gastrointestinal toxicity and infection. During the consolidation phase, the reduced folate carrier polymorphism predicted gastrointestinal toxicity and during continuation. Notably, it was described that in all 3 treatment phases, a glucuronosyltransferase polymorphism could predict the appearance of hyperbilirubinemia and 
Table II. Overview of the genetic loci associated with drug toxicity in response to treatment of leukemia.

\begin{tabular}{|c|c|c|c|c|}
\hline Drug & Gene & Function & Author, year of publication & (Refs.) \\
\hline \multirow[t]{3}{*}{ Mercaptopurine } & $T P M T$ & Enzyme metabolizing thiopurine drugs to & Linga et al, 2014 & $(36)$ \\
\hline & ITPA & inactive compounds; hydrolase influencing & Farfan et al, 2014 & $(35)$ \\
\hline & PACSIN2 & $\begin{array}{l}\text { the metabolism of 6-mercaptopurine links } \\
\text { the actin cytoskeleton with vesicle formation }\end{array}$ & Smid et al, 2016 & $(37)$ \\
\hline \multirow[t]{2}{*}{ Asparaginase } & $A S N S$ & Involved in the synthesis of asparagine binds & Ben Tanfous et al, 2015 & (39) \\
\hline & SOD2 & $\begin{array}{l}\text { to the superoxide byproducts of oxidative } \\
\text { phosphorylation }\end{array}$ & Alachkar et al, 2017 & $(65)$ \\
\hline Vincristine & CEP72 & $\begin{array}{l}\text { Recruitment of key centrosomal proteins to } \\
\text { the centrosome }\end{array}$ & Diouf et al, 2015 & $(40)$ \\
\hline \multirow[t]{9}{*}{ Methotrexate } & SLC19A1 & Regulation of intracellular concentrations of & Liu et al, 2017 & $(43)$ \\
\hline & SLCO1B1 & folate; involved in the removal of drug & Lopez-Lopez et al, 2011 & $(44)$ \\
\hline & $A B C B 1$ & compounds such as statins; decreases drug & Gregers et al, 2015 & $(45)$ \\
\hline & $A B C G 2$ & accumulation in multidrug-resistant cells; & Liu et al, 2017 & $(43)$ \\
\hline & MTHFR & plays a major role in multi-drug resistance; & Umerez et al, 2017 & $(46)$ \\
\hline & $T S$ & plays a role in processing of homocysteine; & Lopez-Lopez et al, 2011 & $(44)$ \\
\hline & SHMT1 & plays a crucial role in the early stages of & Lopez-Lopez et al, 2011 & $(44)$ \\
\hline & $R F C 1$ & DNA biosynthesis; catalyzes the reversible & Lopez-Lopez et al, 2011 & $(44)$ \\
\hline & & $\begin{array}{l}\text { conversion of serine and tetrahydrofolate to } \\
\text { glycine and } 5,10 \text {-methylene tetrahydrofolate } \\
\text { activator of DNA polymerases }\end{array}$ & Lopez-Lopez et al, 2011 & $(44)$ \\
\hline Daunorubicin & CYP3A5 & $\begin{array}{l}\text { Metabolizes drugs and steroid hormones } \\
\text { testosterone and progesterone }\end{array}$ & Huang et al, 2016 & $(50)$ \\
\hline Cytarabine & $D C K$ & $\begin{array}{l}\text { Required for the phosphorylation of several } \\
\text { deoxyribonucleosides and their nucleoside } \\
\text { analogs }\end{array}$ & Gabor et al, 2015 & $(52)$ \\
\hline \multirow[t]{3}{*}{ Glucocorticoids } & $B c l$ & Regulates cell death (apoptosis) plays a & Kaymak Cihan et al, 2017 & $(53)$ \\
\hline & $T S$ & crucial role in the early stages of DNA & Finkelstein et al, 2017 & $(54)$ \\
\hline & $V D R$ & $\begin{array}{l}\text { biosynthesis allows the body to respond } \\
\text { to vitamin D }\end{array}$ & Tantawy et al, 2016 & $(55)$ \\
\hline
\end{tabular}

In the table, overview of the drugs used for the treatment of leukemia, the genes involved in the pharmacogenomics of these drugs, their function and pertinent references are presented.

methotrexate clearance independently associated with hyperbilirubinemia. Analyses adjusted either by self-reported race or by ancestry-informative genetic markers did not influence the above-mentioned genotype-phenotype associations (34).

Mercaptopurine (6-MP). 6-MP is a highly effective chemotherapeutic agent used in the treatment of ALL. It has a narrow therapeutic index and causes hematological and hepatic toxicities. There is an association between toxicity and cumulative toxic plasma concentration of its metabolites, particularly 6-thioguanine nucleotide. The prevalence of polymorphisms in thiopurine S-methyltransferase (TPMT) and iosine triphosphate pyrophosphatase (ITPA) was previously investigated concerning the effects of the 6-MP dosage in 103 Chilean pediatric patients with ALL undergoing maintenance therapy (35). As regards TPMT, when compared with the patients with variant alleles to the wild-type group, it was found that in the maintenance phase, the first group presented lower median daily and cumulative doses of 6-MP. However, no difference was found in 6-MP toxicity or dosage for patients who were carriers of the $\mathrm{P} 32 \mathrm{~T}$ polymorphism when compared to the wild-type group, as regards ITPA. The above observation can be explained by the low prevalence for ITPA (1\%) that was detected in that study. The authors of that study suggested that TMPT genotyping could be an important tool for further optimization of 6-MP treatment design (35). The frequency of TPMT polymorphism and its association with 6-MP-related toxicities was also investigated in a population of 72 children with ALL in South India (36). As regards the hematological toxicity of 6-MP, a previous study included 305 patients during their maintenance therapy with 6-MP and identified that the PACSIN2 rs2413739TT genotype may be a significant risk factor for 6-MP-induced hematological toxicity in patients with wild-type TPMT (37). In addition, Ogungbenro and Aarons (38) developed a physiologically based pharmacokinetic (PBPK) model for 6-MP in order to measure the intracellular metabolism and genetic polymorphism in TPMT activity. This model may be useful to predict 
the plasma 6-MP and tissue concentration of 6-methylmercaptopurine ribonucleotide, 6-MP and 6-thioguanine nucleotide in adults and children. The authors of that study suggested that the model may help to improve 6-MP dosing and the clinical outcome, in order to reduce the related toxicity (38).

Asparaginase. Asparaginase is another standard treatment agent in ALL and its side-effects include allergic reactions, pancreatitis and thrombotic events. Polymorphisms of the asparagine synthetase (ASNS) gene were previously examined in relation to the above-mentioned adverse events in 285 Caucasian children (39). Among these patients, a higher frequency of allergies and pancreatitis was observed in patients who were homozygous for the triple-repeat allele (3R) of the ASNS gene. As a result, patients with the 3R3R genotype may have a higher risk of these toxicities. However, patients with the ASNS haplotype *1 harboring double-repeat (2R) allele had a protection against the above adverse events (39).

Vincristine. Vincristine, a microtubule inhibitor, is a widely used anticancer agent in ALL. Its dose-limiting toxicity is peripheral neuropathy, which exhibits characteristics, such as neuropathic pain and dysfunction (motor, as well as sensory). A polymorphism in the promoter region of the CEP72 gene, namely rs924607, was previously investigated in a study enrolling 321 pediatric patients with ALL concerning vincristine-related neuropathy. An association with an increased risk and severity was proven (40).

Methotrexate (MTX). MTX, an important agent used in the treatment of ALL, may cause severe adverse events and toxicities. The entry of MTX into the cell is mediated by the solute carrier family 19 member 1 (SLC19A1) or the solute carrier organic anion transporter 1B1 (SLCO1B1), and the drug is exported by ATP binding cassette (ABC) transporters, such as ABC subfamily B member 1 (ABCB1) and ABC subfamily $G$ member 2 (ABCG2). The intracellular MTHFR is the key enzyme responsible for folate homeostasis and metabolism. MTX inhibits 2 enzymes: Dihydrofolate reductase and thymidylate synthase (TS). Dihydrofolate reductase converts folates to tetrahydrofolate, which is an active form and a substrate of TS. Subsequently, an inhibition of TS is directly performed by the polyglutamated forms of MTX. As a result, the cells cannot synthesize purines and thymidylate with an inhibition of DNA synthesis (41). The ATP-binding cassette transporter ABCC2, or multidrug-resistance-associated protein 2, exports drugs against concentration gradients at the expense of ATP hydrolysis. This transporter also eliminates MTX from the cell (42).

A large cohort of 499 pediatric patients with ALL was previously used to investigate the pharmacogenetics of MTX (42). The authors proved that kinetics, toxicity and outcome were influenced by germline variants in SLCOIB1, TS and methylenetetrahydrofolatereductase (42). In addition, a study on 12 SNPs in the transporter genes category (SLC19A1, $S L C O 1 B 1, A B C B 1$ and $A B C G 2$ ) of 322 Chinese children with ALL yielded the following results: The $S L C O 1 B$ rs10841753 SNP was significantly associated with plasma MTX levels in 48 patients, and the $A B C B 1$ rs1128503 SNP C allele was associated with a longer duration of hospitalization than the TT genotype, whereas oral mucositis was not associated to any polymorphism (43). The fact that MTX-related toxicity is predicted by polymorphisms of the $S L C O 1 B 1$ gene in childhood ALL was also presented in a study that included 115 Spanish pediatric patients with B-ALL (44). The analysis was performed on 10 different polymorphisms of 7 genes (MTHFR, TS, SHMT1, RFCl, ABCB1, ABCG2 and SLCO1B1). Two SNPs (rs4149081 and rs11045879) of the SLCO1B1 gene were found to be significantly associated with MTX plasma concentration, whereas no other significant association was found in the other polymorphisms analyzed (44).

Furthermore, the association of the $A B C B 1$ polymorphisms in liver toxicity after high-dose MTX was confirmed in a Danish population-based study including 522 patients with ALL (45). In the framework of that study, patients with the 3435TT genotype, when compared with patients with the 3435CT or 3435CC genotype, were found to exhibit a higher degree of bone marrow toxicity during doxorubicin, vincristine and prednisolone induction therapy. Furthermore, the patients with $3435 \mathrm{CC}$ genotype presented higher liver toxicity following treatment with high-dose MTX in comparison with patients with the 3435CT/TT genotype (45).

As regards $M T H F R$, the above-mentioned results are similar to the results of another study focusing in the MTHFR polymorphisms and their effects on MTX therapy; the MTHFR C677T and A1298C alleles were not proven to predict MTX-related toxicity and/or outcome in pediatric ALL (46). Similar results were derived from a systematic review and meta-analysis performed by Lopez-Lopez et al in 2013 (47); MTHFR C677T and A1298C alleles did not predict MTX-related toxicity in pediatric ALL. Another polymorphism that was investigated in the same framework, referred to MTX toxicity, is CCND1 G870A (cyclin D1 gene). A significant association was revealed between this SNP and an increased risk of MTX-related hepatotoxicity (48). Finally, the potential association between the $R F C 1$ G80A polymorphism and MTX-related toxicity was previously investigated in a meta-analysis including children with ALL; however, effects of this polymorphism on MTX-related toxicity were detected (49). Folylpolyglutamate synthetase (FPGS) is a catalase with an important role in the metabolism of MTX. The FPGS rs1544105 SNP was previously analyzed in 57 pediatric patients with ALL. Patients with the AA genotype compared to those with the GG or GA genotype exhibited a significantly higher 24-h MTX plasma concentration of MTX, while no differences were found after $44 \mathrm{~h}$ (50).

Daunorubicin (DNR). DNR is a chemotherapeutic which belongs to anthracyclines, with limitations due to accumulated cardiotoxicity. Polymorphisms of the cytochrome P450 family 3 subfamily A member 5 (CYP3A5) gene, which is involved in the clearance of DNR metallization, was previously investigated in a study on 36 children with ALL; the authors of that study revealed an association between the $C Y P 3 A 5 * 3$ gene polymorphism and the mRNA expression of $C Y P 3 A 5$, the enzyme activity of CYP3A, the concentration of DNR in plasma and adverse reactions (51).

Cytarabine (cytosine arabinoside, Ara-C). Ara-C is another chemotherapeutic agent used in the treatment of ALL. In total, 8 SNPs of the cytidine deaminase $(C D A)$, deoxycytidine 
kinase $(D C K)$, DCMP deaminase (DCTD), SLC28A3 and $S L C 29 A 1$ genes were previously investigated in 144 children with ALL; the rs12648166 and rs4694362 SNPs of the DCK gene were found to be associated with hematologic toxicity, thus indicating that $D C K$ polymorphisms may be important genetic risk factors for hematologic toxicity (52).

Glucocorticoids (GCs). GCs are one of the main drugs used in the treatment of ALL; however, they cause severe side-effects (metabolic, nutritional, endocrine, gastrointestinal, hepatic, musculoskeletal, connective tissue, psychiatric, nervous system, eye, cardiac and vascular disorders, and infections) with individual variation. Two polymorphisms of the glucocorticoid receptor gene $N R 3 C 1, \mathrm{~N} 363 \mathrm{~S}$ and $\mathrm{Bcl} /$, were previously investigated tested in a study on 46 pediatric patients with ALL; no role of the N363S polymorphism was detected in either of the groups, although an association was found between patients with the Bcl/polymorphism and more frequent side-effects (53). Pediatric patients with ALL may also experience bone toxicity, such as bone fractures and osteonecrosis, and the development of osteoporosis, which has been associated with exposure to corticosteroids (alteration of osteoblastic activity), MTX (alteration of bone formation) and an age $>10$ years. A genetic variant of the TS polymorphism (2R/2R TS genotype) was found to increase the risk of developing osteonecrosis among patients $<10$ years at the time of diagnosis and to increase the risk of suffering from bone fractures among older children, in a study that included 615 children with ALL (54). Osteoporosis is a multifactorial disease, characterized by the increased risk of fragility fractures and a reduced bone mineral density (BMD). The vitamin $\mathrm{D}$ receptor $(V D R)$ gene is a gene that plays a role in the modification of BMD. Its TT genotype has been shown to be associated with an increased BMD in a study that included 40 newly diagnosed Egyptian pediatric patients with ALL (55).

In addition, the vitamin D receptor (VDR) Fok1, as well as the collagen protein CollAl Spl-binding site gene polymorphisms, which play a role in bone mineral and matrix formation, were previously investigated for their role in bone complications due to therapy in 50 pediatric patients with ALL, who were treated with the ALL Berlin-Frankfurt-Muenster-95 protocol between 1998 and 2008. A higher risk of therapy-induced bone mineral loss and osteonecrosis was found in patients aged $\geq 10$ years and with vitamin D deficiency (56).

As regards hematological toxicity, Glisovic et al (57) investigated whether, in association with treatment, polymorphisms of the DARC and CXCL2 genes, as well as in the ORMDL3-GSDMA-CSF3 locus on chromosome 17q21 may influence the risk of complications due to therapy. A total of 21 SNPs of the above-mentioned genes were analyzed with regard to neutropenia and infection in 286 Caucasian children with ALL. A higher risk of developing neutropenia and hospitalization due to neutropenia and fever was associated with the DARC rs3027012 SNP, located in the 5'-UTR. The $D A R C$ rs12075 A to $\mathrm{G}$ substitution was associated with a protective effect. The SNP rs3859192 in the GSDMA and the rs16850408 SNP of CXCL2 gene were associated with an increased risk of hospitalization due to infection and infection, respectively (57). Finally, another study including 97 pediatric patients with ALL genotyped for the CYP1A1, GSTP1
Ile105Val and XRCC1 Arg194Trp SNPs, and examined their putative association with toxicity (58). An association between the XRCC1 Arg194Trp SNP and a higher drug toxicity was revealed; in particular, a higher risk of myelosuppression was revealed for carriers of the $\mathrm{CT}$ and TT genotypes, compared to those with the wild-type CC genotype (58).

Furthermore, in another study, the role of miRNAs in the regulation of the expression of pharmacokinetic/pharmacodynamic pathway genes was investigated; that study was on mucositis in 179 Spanish children with B-cell precursor ALL homogeneously treated with LAL/SHOP protocols (59). A total of 160 SNPs were analyzed and 3 SNPs in miR-4268, miR-4751 and miR-3117 were detected to be associated with mucositis, diarrhea and vomiting, respectively (59).

\section{Prognosis/outcomes}

A previous study including 320 patients with ALL, of which 68 relapsed or died due to disease within 5 years of follow-up, examined the role of functional SNPs in genes encoding carcinogen-metabolizing enzymes (CYP1A1, CYP2D6, CYP2E1, MPO, GSTM1, GSTT1, GSTP1, NAT1, NAT2 and NQO1), as well as DNA-repair enzymes ( $h M L H 1, h M S H 3, X R C C 1, X P F$ and $A P E$ ). A worse disease prognosis was observed in carriers of the $C Y P 1 A I^{*} 2 \mathrm{~A}$ and $N Q O 1^{*} 2$ variants, and a combination of $h M L H 1$ Ile219 with the $C Y P 1 A 1 * 2 A$ variant increased the risk of relapse (60).

The effect of promoter polymorphisms in key regulators of the intrinsic apoptosis pathway on the prognosis of childhood ALL was previously investigated in a study on 321 patients, considering that the hematopoietic system belongs to tissues with a high intrinsic proliferative capacity (61). A systematic analysis of the proximal promoter regions of 21 apoptotic genes was performed. The authors of that study demonstrated that promoter variations in 11 intrinsic apoptosis genes (ADPRT, APAF1, BCL2, BAD, BID, MCL1, BIRC4, BCL2L1, ENDOG, $Y W H A B$ and $Y W H A Q$ ) affected the promoter activity in an allele-specific manner. For the MCL1 gene in particularly, a reduced overall survival among high-risk patients receiving higher doses of corticosteroids was associated with promoter variation and an increased expression. The authors of that study also suggested that an increased expression of this anti-apoptotic gene may be associated with reduced cell death and a response to treatment, which is associated to disease and to the dose (61).

Furthermore, another gene involved in apoptotic cell death is the Fas gene, the promoter of which has 2 SNPs involved in ALL, in particular-1377G/A and -670 A/G. A study including 142 patients revealed an association of the Fas GG genotype at position-670 with liver involvement and was suggested to play a significant role in the prognosis of ALL (62). Gregers et al, in 2015, suggested that $A B C B 1$ 1199G4A could predict the outcome of ALL in children (45). Accordingly, in that study which included 522 patients, a 2.9-fold increased risk of relapse was observed for patients with the 1199GA genotype vs. the 1199GG genotype, and a reduced risk of 61 and $40 \%$, respectively, for patients with the $3435 \mathrm{CT}$ or $3435 \mathrm{TT}$ genotypes vs. the 3435CC genotype (45). The rs1544105 SNP of the FPGS gene was investigated in 57 pediatric patients with ALL; patients with AA genotype exhibited a longer median 
survival and significant difference in overall survival than those carrying GG or GA (50).

A study including 140 Argentinian patients with an age $<20$ years with ALL revealed that GST polymorphisms led to an increased risk of relapse and a lower recurrence-free survival (RFS) of patients with childhood ALL (63). In detail, patients were genotyped for the following polymorphisms: GSTP1 313A/G, MDR1 3435T/C, MTHFR 665C/T, GSTT1 null and GSTM1 null. An increased risk of relapse was observed for patients with the GSTP1 313GG genotype, the combined genotype slightly increased the risk of relapse for patients with the 2/3-risk-genotypes (GSTT1 null, GSTM1 null, GSTP1313GG) and the RFS was shorter in patient with the GSTP1313GG $(\mathrm{P}=0.025)$ and 2/3-risk-genotypes (63). Finally, another study including 322 Chinese children with ALL, genotyped for 12 polymorphisms, demonstrated that patients with the SLCO1BI rs4149056 CC genotype had a worse long-term outcome compared to patients with the TT or TC genotypes; in addition, patients with the SCL19A1 rs2838958 AA genotype exhibited a worse outcome compared to patients with the AG or GG genotypes (43).

Another study included 153 donors and 153 children with ALL, AML or juvenile myelomonocytic leukemia following allogeneic hematopoietic stem cell transplantation (HSCT). All of the patients were genotyped for the rs3087243, rs 231775 and rs4553808 SNPs of the CTLA-4 gene. A significant association was observed between the donor's CLTA-4 genotype of rs3087243 SNP and transplant-related mortality (TRM) following HSCT, thus suggesting that the CTLA-4 polymorphisms may be associated with an increased risk of TRM and may thus affect the survival of children undergoing allogeneic HSCT (64).

\section{Conclusion}

Several epidemiological studies have investigated the role of genetic factors as possible risk factors for ALL and have proven their role in leukemogenesis. Furthermore, various genetic studies have demonstrated the association between polymorphisms of genes that regulate inflammation, tumor suppression and metabolism with susceptibility, drug-induced toxicity and outcome of ALL. Despite the progress that has already been made, the field of polymorphisms remains a real challenge for future research concerning childhood ALL.

\section{Acknowledgements}

Not applicable.

\section{Funding}

No funding was received.

\section{Availability of data and materials}

Not applicable.

\section{Authors' contributions}

EK, GNG and ES conceived and designed the study and drafted the manuscript. EK and GNG searched the literature and selected the relevant articles. EK and GNG analyzed the articles from literature. ES critically revised the article for important intellectual content. All authors have read and approved the final manuscript.

\section{Ethics approval and consent to participate}

Not applicable.

\section{Patient consent for publication}

Not applicable.

\section{Competing interests}

The authors declare that they have no competing interests.

\section{References}

1. Li YY, Gao W, Pang SS, Min XY, Yang ZJ, Wang H, Lu XZ, Wang LS, Wang XM, Qian Y, et al: TAP1 I333V gene polymorphism and type 1 diabetes mellitus: A meta-analysis of 2248 cases. J Cell Mol Med 18: 929-937, 2014.

2. Glessner JT, Bick AG, Ito K, Homsy J, Rodriguez-Murillo L, Fromer M, Mazaika E, Vardarajan B, Italia M, Leipzig J, et al: Increased frequency of de novo copy number variants in congenital heart disease by integrative analysis of single nucleotide polymorphism array and exome sequence data. Circ Res 115: 884-896, 2014

3. Ziegler DA, Ashourian P, Wonderlick JS, Sarokhan AK, Prelec D, Scherzer CR and Corkin S: Motor impulsivity in Parkinson disease: Associations with COMT and DRD2 polymorphisms. Scand J Psychol 55: 278-286, 2014.

4. Zhang J, Zhang J, Wu D, Wang J and Dong W: Associations between TNFSF15 polymorphisms and susceptibility to ulcerative colitis and Crohn's disease: A meta-analysis. Autoimmunity 47: 512-518, 2014.

5. Zhou LP, Yao F, Luan H, Wang YL, Dong XH, Zhou WW and Wang QH: CYP3A4*1B polymorphism and cancer risk: A HuGE review and meta-analysis. Tumour Biol 34: 649-660, 2013.

6. Weng Y, Zhang J, Tang X, Xie X and Chen G: Thymidylate synthase polymorphisms and hematological cancer risk: A meta-analysis. Leuk Lymphoma 53: 1345-1351, 2012.

7. Wang Y, Miller S, Roulston D, Bixby D and Shao L: Genome-wide single-nucleotide polymorphism array analysis improves prognostication of acute lymphoblastic leukemia/lymphoma. J Mol Diagn 18: 595-603, 2016.

8. Belson M, Kingsley B and Holmes A: Risk factors for acute leukemia in children: A review. Environ Health Perspect 115: 138-145, 2007.

9. Vijayakrishnan J and Houlston RS: Candidate gene association studies and risk of childhood acute lymphoblastic leukemia: A systematic review and meta-analysis. Haematologica 95: 1405-1414, 2010.

10. Lu J, Zhao Q, Zhai YJ, He HR, Yang LH, Gao F, Zhou RS, Zheng $J$ and Ma XC: Genetic polymorphisms of CYP1A1 and risk of leukemia: A meta-analysis. Onco Targets Ther 8: 2883-2902, 2015.

11. Han F, Tan Y, Cui W, Dong L and Li W: Novel insights into etiologies of leukemia: A HuGE review and meta-analysis of CYP1A1 polymorphisms and leukemia risk. Am J Epidemiol 178: 493-507, 2013.

12. Huang GZ, Shan W, Zeng L and Huang LG: The GSTP1 A1578G polymorphism and the risk of childhood acute lymphoblastic leukemia: Results from an updated meta-analysis. Genet Mol Res 12: 2481-2491, 2013.

13. Zhao T, Ma F and Yin F: Role of polymorphisms of GSTM1, GSTT1 and GSTP1 Ile105Val in childhood acute lymphoblastic leukemia risk: An updated meta-analysis. Minerva Pediatr 70: 185-196, 2018.

14. Krajinovic M, Lamothe S, Labuda D, Lemieux-Blanchard E, Theoret Y, Moghrabi A and Sinnett D: Role of MTHFR genetic polymorphisms in the susceptibility to childhood acute lymphoblastic leukemia. Blood 103: 252-257, 2004. 
15. de Jonge R, Tissing WJ, Hooijberg JH, Jansen G, Kaspers GJ, Lindemans J, Peters GJ and Pieters R: Polymorphisms in folate-related genes and risk of pediatric acute lymphoblastic leukemia. Blood 113: 2284-2289, 2009.

16. Milne E, Greenop KR, Scott RJ, Haber M, Norris MD, Attia J, Jamieson SE, Miller M, Bower C, Bailey HD, et al: Folate pathway gene polymorphisms, maternal folic acid use, and risk of childhood acute lymphoblastic leukemia. Cancer Epidemiol Biomarkers Prev 24: 48-56, 2015.

17. Kreile M, Rots D, Piekuse L, Cebura E, Grutupa M, Kovalova Z and Lace B: Lack of association between polymorphisms in genes MTHFR and MDR1 with risk of childhood acute lymphoblastic leukemia. Asian Pac J Cancer Prev 15: 9707-9711, 2014.

18. Qiao Z, Lou D and Ruan L: TSER polymorphism is not associated with risk of pediatric acute lymphoblastic leukemia: A meta-analysis. Medicine (Baltimore) 96: e6143, 2017.

19. Ma LM, Yang HP, Yang XW and Ruan LH: Methionine synthase A2756G polymorphism influences pediatric acute lymphoblastic leukemia risk: A meta-analysis. Biosci Rep 39: BSR20181770, 2019.

20. Tijchon E, Havinga J, van Leeuwen FN and Scheijen B: B-lineage transcription factors and cooperating gene lesions required for leukemia development. Leukemia 27: 541-552, 2013.

21. Kastner P, Dupuis A, Gaub MP, Herbrecht R, Lutz P and Chan S: Function of Ikaros as a tumor suppressor in B cell acute lymphoblastic leukemia. Am J Blood Res 3: 1-13, 2013.

22. Kuiper RP, Waanders E, van der Velden VH, van Reijmersdal SV, Venkatachalam R, Scheijen B, Sonneveld E, van Dongen JJ, Veerman AJ, van Leeuwen FN, et al: IKZF1 deletions predict relapse in uniformly treated pediatric precursor B-ALL. Leukemia 24: 1258-1264, 2010.

23. Mullighan CG, Su X, Zhang J, Radtke I, Phillips LA, Miller CB, Ma J, Liu W, Cheng C, Schulman BA, et al: Deletion of IKZF1 and prognosis in acute lymphoblastic leukemia. N Engl J Med 360: 470-480, 2009

24. Papaemmanuil E, Hosking FJ, Vijayakrishnan J, Price A, Olver B, Sheridan E, Kinsey SE, Lightfoot T, Roman E, Irving JA, et al: Loci on $7 \mathrm{p} 12.2,10 \mathrm{q} 21.2$ and $14 \mathrm{q} 11.2$ are associated with risk of childhood acute lymphoblastic leukemia. Nat Genet 41: 1006-1010, 2009.

25. Rudant J, Orsi L, Bonaventure A, Goujon-Bellec S, Baruchel A, Petit A, Bertrand Y, Nelken B, Pasquet M, Michel G, et al: ARID5B, IKZF1 and non-genetic factors in the etiology of childhood acute lymphoblastic leukemia: The ESCALE study. PLoS One 10: e0121348, 2015.

26. Archer NP, Perez-Andreu V, Stoltze U, Scheurer ME, Wilkinson AV, Lin TN, Qian M, Goodings C, Swartz MD, Ranjit N, et al: Family-based exome-wide association study of childhood acute lymphoblastic leukemia among hispanics confirms role of ARID5B in susceptibility. PLoS One 12: e0180488, 2017

27. Xu H, Yang W, Perez-Andreu V, Devidas M, Fan Y, Cheng C, Pei D, Scheet P, Burchard EG, Eng C, et al: Novel susceptibility variants at 10p12.31-12.2 for childhood acute lymphoblastic leukemia in ethnically diverse populations. J Natl Cancer Inst 105: 733-742, 2013

28. Walsh KM, de Smith AJ, Hansen HM, Smirnov IV, Gonseth S, Endicott AA, Xiao J, Rice T, Fu CH, McCoy LS, et al: A heritable missense polymorphism in CDKN2A confers strong risk of childhood acute lymphoblastic leukemia and is preferentially selected during clonal evolution. Cancer Res 75: 4884-4894, 2015.

29. Bhandari P, Ahmad F, Mandava S and Das BR: Association of genetic variants in ARID5B, IKZF1 and CEBPE with risk of childhood de novo B-lineage acute lymphoblastic leukemia in India. Asian Pac J Cancer Prev 17: 3989-3995, 2016.

30. Hou Q, Liao F, Zhang S, Zhang D, Zhang Y, Zhou X, Xia X, Ye Y, Yang H, Li Z, et al: Regulatory network of GATA3 in pediatric acute lymphoblastic leukemia. Oncotarget 8: 36040-36053, 2017.

31. de Lourdes Perim A, Guembarovski RL, Oda JM, Lopes LF Ariza CB, Amarante MK, Fungaro MH, de Oliveira KB and Watanabe MA: CXCL12 and TP53 genetic polymorphisms as markers of susceptibility in a Brazilian children population with acute lymphoblastic leukemia (ALL). Mol Biol Rep 40: 4591-4596, 2013

32. Hashemi M, Bahari G, Naderi M, Sadeghi Bojd S and Taheri M: Association of lnc-LAMC2-1:1 rs2147578 and CASC8 rs10505477 Polymorphisms with risk of childhood acute lymphoblastic leukemia. Asian Pac J Cancer Prev 17: 4985-4989, 2016.
33. Xue Y, Yang X, Hu S, Kang M, Chen J and Fang Y: A genetic variant in miR-100 is a protective factor of childhood acute lymphoblastic leukemia. Cancer Med 8: 2553-2560, 2019.

34. Kishi S, Cheng C, French D, Pei D, Das S, Cook EH, Hijiya N, Rizzari C, Rosner GL, Frudakis T, et al: Ancestry and pharmacogenetics of antileukemic drug toxicity. Blood 109: 4151-4157, 2007.

35. Farfan MJ, Salas C, Canales C, Silva F, Villarroel M, Kopp K, Torres JP, Santolaya ME and Morales J: Prevalence of TPMT and ITPA gene polymorphisms and effect on mercaptopurine dosage in Chilean children with acute lymphoblastic leukemia. BMC Cancer 14: 299, 2014.

36. Linga VG, Patchva DB, Mallavarapu KM, Tulasi V, Kalpathi KI, Pillai A, Gundeti S, Rajappa SJ and Digumarti R: Thiopurine methyltransferase polymorphisms in children with acute lymphoblastic leukemia. Indian J Med Paediatr Oncol 35: 276-280, 2014

37. Smid A, Karas-Kuzelicki N, Jazbec J and Mlinaric-Rascan I: PACSIN2 polymorphism is associated with thiopurine-induced hematological toxicity in children with acute lymphoblastic leukaemia undergoing maintenance therapy. Sci Rep 6: 30244 , 2016.

38. Ogungbenro K and Aarons L; CRESim \& Epi-CRESim Project Groups: Physiologically based pharmacokinetic model for 6-mercpatopurine: Exploring the role of genetic polymorphism in TPMT enzyme activity. Br J Clin Pharmacol 80: 86-100, 2015.

39. Ben Tanfous M, Sharif-Askari B, Ceppi F, Laaribi H, Gagne V, Rousseau J, Labuda M, Silverman LB, Sallan SE, Neuberg D, et al: Polymorphisms of asparaginase pathway and asparaginase-related complications in children with acute lymphoblastic leukemia. Clin Cancer Res 21: 329-334, 2015.

40. Diouf B, Crews KR, Lew G, Pei D, Cheng C, Bao J, Zheng JJ, Yang W, Fan Y, Wheeler HE, et al: Association of an inherited genetic variant with vincristine-related peripheral neuropathy in children with acute lymphoblastic leukemia. JAMA 313 815-823, 2015

41. Huang L, Tissing WJ, de Jonge R, van Zelst BD and Pieters R: Polymorphisms in folate-related genes: Association with side effects of high-dose methotrexate in childhood acute lymphoblastic leukemia. Leukemia 22: 1798-1800, 2008.

42. Radtke S, Zolk O, Renner B, Paulides M, Zimmermann M, Möricke A, Stanulla M, Schrappe M and Langer T: Germline genetic variations in methotrexate candidate genes are associated with pharmacokinetics, toxicity, and outcome in childhood acute lymphoblastic leukemia. Blood 121: 5145-5153, 2013.

43. Liu SG, Gao C, Zhang RD, Zhao XX, Cui L, Li WJ, Chen ZP, Yue ZX, Zhang YY, Wu MY, et al: Polymorphisms in methotrexate transporters and their relationship to plasma methotrexate levels, toxicity of high-dose methotrexate, and outcome of pediatric acute lymphoblastic leukemia. Oncotarget 8: 37761-37772, 2017.

44. Lopez-Lopez E, Martin-Guerrero I, Ballesteros J, Piñan MA, Garcia-Miguel P, Navajas A and Garcia-Orad A: Polymorphisms of the SLCO1B1 gene predict methotrexate-related toxicity in childhood acute lymphoblastic leukemia. Pediatr Blood Cancer 57: 612-619, 2011.

45. Gregers J, Gréen H, Christensen IJ, Dalhoff K, Schroeder H, Carlsen N, Rosthoej S, Lausen B, Schmiegelow K and Peterson C: Polymorphisms in the ABCB1 gene and effect on outcome and toxicity in childhood acute lymphoblastic leukemia. Pharmacogenomics J 15: 372-379, 2015.

46. Umerez M, Gutierrez-Camino Á, Muñoz-Maldonado C, Martin-Guerrero I and Garcia-Orad A: MTHFR polymorphisms in childhood acute lymphoblastic leukemia: Influence on methotrexate therapy. Pharmgenomics Pers Med 10: 69-78, 2017.

47. Lopez-Lopez E, Ballesteros J, Piñan MA, Sanchez de Toledo J, Garcia de Andoin N, Garcia-Miguel P, Navajas A and Garcia-Orad A: Polymorphisms in the methotrexate transport pathway: A new tool for MTX plasma level prediction in pediatric acute lymphoblastic leukemia. Pharmacogenet Genomics 23 . 53-61, 2013.

48. Xue Y, Rong L, Tong N, Wang M, Zhang Z and Fang Y: CCND1 G870A polymorphism is associated with toxicity of methotrexate in childhood acute lymphoblastic leukemia. Int J Clin Exp Pathol 8: 11594-11600, 2015.

49. He HR, Liu P, He GH, Dong WH, Wang MY, Dong YL and Lu J: Association between reduced folate carrier G80A polymorphism and methotrexate toxicity in childhood acute lymphoblastic leukemia: A meta-analysis. Leuk Lymphoma 55: 2793-2800, 2014. 
50. Huang Z, Tong HF, Li Y, Qian JC, Wang JX, Wang Z and Ruan JC: Effect of the polymorphism of folylpolyglutamate synthetase on treatment of high-dose methotrexate in pediatric patients with acute lymphocytic leukemia. Med Sci Monit 22: 4967-4973, 2016.

51. Huang Z, Wang J, Qian J, Li Y, Xu Z, Chen M and Tong H: Effects of cytochrome P450 family 3 subfamily A member 5 gene polymorphisms on daunorubicin metabolism and adverse reactions in patients with acute leukemia. Mol Med Rep 15: 3493-3498, 2017.

52. Gabor KM, Schermann G, Lautner-Csorba O, Rarosi F, Erdelyi DJ, Endreffy E, Berek K, Bartyik K, Bereczki C, Szalai C and Semsei AF: Impact of single nucleotide polymorphisms of cytarabine metabolic genes on drug toxicity in childhood acute lymphoblastic leukemia. Pediatr Blood Cancer 62: 622-628, 2015.

53. Kaymak Cihan M, Karabulut HG, Yürür Kutlay N, Ilgın Ruhi H, Tükün A and Olcay L: Association between N363S and BclI polymorphisms of the glucocorticoid receptor gene (NR3C1) and glucocorticoid side effects during childhood acute lymphoblastic leukemia treatment. Turk J Haematol 34: 151-158, 2017.

54. Finkelstein Y, Blonquist TM, Vijayanathan V, Stevenson KE, Neuberg DS, Silverman LB, Vrooman LM, Sallan SE and Cole PD: A thymidylate synthase polymorphism is associated with increased risk for bone toxicity among children treated for acute lymphoblastic leukemia. Pediatr Blood Cancer 64, 2017.

55. Tantawy M, Amer M, Raafat T and Hamdy N: Vitamin D receptor gene polymorphism in Egyptian pediatric acute lymphoblastic leukemia correlation with BMD. Meta Gene 9: 42-46, 2016.

56. Erdem M, Tüfekçi Ö, Kızıldağ S, Yılmaz Ş, Kızmazoğlu D, Eroğlu Filibeli B and Ören H: Investigation of the relationship between Fok 1 and Col1A1 gene polymorphisms and development of treatment-related bone complications in children with acute lymphoblastic leukemia. Turk J Haematol 36: 12-18, 2019.

57. Glisovic SJ, Pastore YD, Gagne V, Plesa M, Laverdière C, Leclerc JM, Sinnett D and Krajinovic M: Impact of genetic polymorphisms determining leukocyte/neutrophil count on chemotherapy toxicity. Pharmacogenomics J 18: 270-274, 2018.

58. Abo-Bakr A, Mossallam G, El Azhary N, Hafez H and Badawy R: Impact of CYP1A1, GSTP1 and XRCC1 genes polymorphisms on toxicity and response to chemotherapy in childhood acute lymphoblastic leukemia. J Egypt Natl Canc Inst 29: 127-133, 2017.
59. Gutierrez-Camino Á, Umerez M, Lopez-Lopez E, SantosZorrozua B, Martin-Guerrero I, de Andoin NG, Ana S, Navajas A, Astigarraga I and Garcia-Orad A: Involvement of miRNA polymorphism in mucositis development in childhood acute lymphoblastic leukemia treatment. Pharmacogenomics 19: 1403-1412, 2018.

60. Krajinovic M, Labuda D, Mathonnet G, Labuda M, Moghrabi A, Champagne J and Sinnett D: Polymorphisms in genes encoding drugs and xenobiotic metabolizing enzymes, DNA repair enzymes, and response to treatment of childhood acute lymphoblastic leukemia. Clin Cancer Res 8: 802-810, 2002.

61. Sanchez R, St-Cyr J, Lalonde ME, Healy J, Richer C, Gagne V, Laverdiere C, Silverman LB, Sallan SE, Neuberg D, et al: Impact of promoter polymorphisms in key regulators of the intrinsic apoptosis pathway on the outcome of childhood acute lymphoblastic leukemia. Haematologica 99: 314-321, 2014.

62. Valibeigi B, Amirghofran Z, Golmoghaddam H, Hajihosseini R and Kamazani FM: Fas gene variants in childhood acute lymphoblastic leukemia and association with prognosis. Pathol Oncol Res 20: 367-374, 2014.

63. Leonardi DB, Abbate M, Riccheri MC, Nuñez M, Alfonso G, Gueron G, De Siervi A, Vazquez E and Cotignola J: Improving risk stratification of patients with childhood acute lymphoblastic leukemia: Glutathione-S-Transferases polymorphisms are associated with increased risk of relapse. Oncotarget 8: 110-117, 2017.

64. Hammrich J, Wittig S, Ernst T and Gruhn B: CTLA-4 polymorphisms: Influence on transplant-related mortality and survival in children undergoing allogeneic hematopoietic stem cell transplantation. J Cancer Res Clin Oncol 144: 587-592, 2018.

65. Alachkar H, Fulton N, Sanford B, Malnassy G, Mutonga M, Larson RA, Bloomfield CD, Marcucci G, Nakamura Y and Stock W: Expression and polymorphism (rs4880) of mitochondrial superoxide dismutase (SOD2) and asparaginase induced hepatotoxicity in adult patients with acute lymphoblastic leukemia. Pharmacogenomics J 17: 274-279, 2017.

This work is licensed under a Creative Commons Attribution-NonCommercial-NoDerivatives 4.0 International (CC BY-NC-ND 4.0) License. 